\title{
Evaluation of two regional anesthetic methods on the front limb of dogs using hyperbaric bupivacaine $^{1}$
}

\author{
Avaliação de dois métodos de bloqueios anestésicos regionais no membro anterior em cães \\ usando bupivacaína hiperbárica
}

\author{
Gustavo Guerino MacedoI, Rafael DeRossiII, Fabrício Oliveira Frazílio ${ }^{\text {III }}$

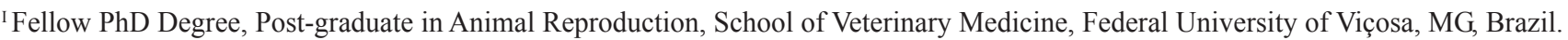 \\ ${ }^{\text {II }} \mathrm{PhD}$, Associate Professor, Department Veterinary Medicine, Surgery and Anesthesiology, Faculty of Veterinary Medicine and Animal Science, UFMS, \\ Campo Grande-MS, Brazil.

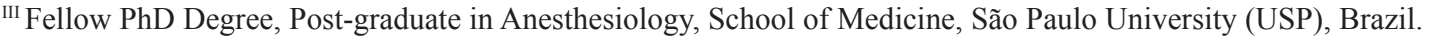

\begin{abstract}
Purpose: To evaluate the effects of bupivacaine 0.5 and $0.25 \%$ in intravenous regional anesthesia (IVRA) and brachial plexus block (BPB), respectively, on anesthesia, motor block and cardiovascular parameters in dogs. Methods: Fourteen healthy adult dogs averaging 10 kilograms $(\mathrm{kg})$ of body weight. Animals were randomly assigned to receive one of the two treatments IVRA (n=7) or BPB (n=7). All the animals were sedated with acepromazine $(0.1 \mathrm{mg} / \mathrm{kg}$ intramuscular). To execute the BPB was used an electrical nerve stimulation. Anesthesia, motor block, sedation, cardiovascular and respiratory effects were measured as effect of the treatment. Results: BPA showed superior efficiency and duration of anesthesia (BPB - $456 \pm 94$ minutes vs IVRA - 138 \pm 44 ) as well as motor block. There only physiologic parameter which change were the systolic pressure in BPB and respiratory rate for both treatments. Conclusion: In dogs the $0.25 \%$ hyperbaric bupivacaine in BPB produces a front limb anesthesia about three times more than the $0.5 \%$ in IVRA, with ptosis of the limb blocked and little interference in the cardiovascular system but with decrease in respiratory rate.
\end{abstract}

Key words: Anesthesia. Forelimb. Bupivacaine. Dogs.

\section{RESUMO}

Objetivo: Avaliar os efeitos da bupivacaína 0,5 e $0,25 \%$ na anestesia regional endovenosa (IVRA) e no bloqueio do plexo braquial (BPB) respectivamente, na anestesia, bloqueio motor e parâmetros cardiovasculares em cães. Métodos: Foram utilizados 14 cães sadios adultos pesando em média 10 kilos. Animais foram aleatoriamente designados a um de dois tratamentos IVRA $(n=7)$ ou BPB $(n=7)$. Todos os animais foram sedados com acepromazina $(0,1 \mathrm{mg} / \mathrm{kg}$ intramuscular). Para realizar o BPB foi usado um estimulador elétrico nervoso. Anestesia, bloqueio motor, sedação, efeitos cardiovascular e respiratório foram mensurados como efeitos dos respectivos bloqueios. Resultados: O bloqueio BPB demonstrou eficiência superior e maior duração da anestesia (BPB - $456 \pm 94$ minutos vs IVRA $-138 \pm 44$ minutos) bem como maior envolvimento motor. Somente a pressão arterial sistólica foi alterada no grupo BPB e a freqüência respiratória em ambos os tratamentos. Conclusão: Em cães, a bupivacaína $0,25 \%$ hiperbárica no grupo BPB produziu uma anestesia do membro anterior três vezes mais longa que a $0,5 \%$ no grupo IVRA, com ptose do membro bloqueado e pequena interferência no sistema cardiovascular e com diminuição da freqüência respiratória.

Descritores: Anestesia. Membro Anterior. Bupivacaína. Cães.

${ }^{1}$ Research performed at the Laboratory of Experimental Anesthesia, Faculty of Veterinary Medicine and Animal Science, Federal University of Mato Grosso do Sul (UFMS), Brazil.

\section{Introduction}

The inhalatory or venous general anesthesia is not applied for many patients who need surgery in front limbs. It is due, because some alterations as pregnancy, age, obesity and pathologies involving the renal, pulmonary or hepatic systems can limit the utilization of these anesthetic methods. In this sense, a viable alternative are the regional blocks, where have been grew the interest due to the lower systemic interference, low toxicity and the reduced cost. The biggest limitations in these techniques are the low anatomic knowledge and front attempts without success from the veterinary anesthetists' professionals.

In human medicine, the regional techniques are the favorite choice from anesthesiologists for surgeries in front limbs; moreover these techniques can be helpful in veterinary medicine as well, when adequately used. For small animals, the main blocks in front limb surgeries bellow the scapula-humeral articulation are the brachial plexus block (BPB) and intravenous regional anesthesia (IVRA). However, these techniques are sub utilized because, as in BPB, the anesthetics being deposited with 
no enough anatomic knowledge occurring an error between the local of the deposition of the drug and the nervous fibers to be blocked. In this way, one alternative method to solve this problem would be the exact localization of the fibers using an electrical nerve stimulation, based on the observation that and electrical pulse of low current applied on peripheral nervous fiber will produce a stimulation in motor fibers, identifying in this way the proximity of the nerve without a contact with the needle and a possible neuronal lesion. An ideal electrical nerve stimulator should have variable amperage output to provide a use of a high current in the exploration phase and progressively decreasing of the current to register the proximity of the nerve. Furthermore, studies suggest that the needle can be positioned extremely close to the nerve; thereby this system can improve the accuracy of the local anesthetic block and increasing the success rate of the procedure mainly to less experienced anesthesiologists ${ }^{1,2}$.

On the other hand, the IVRA is a relatively simple technique where anesthetic is injected in the radial or cephalic vein below an occlusive tourniquet in the front limbs in dogs; however has the inconvenient possibility to produce lesion in myocardium as well as central nervous system (CNS) intoxication. This technique is called too as Bier block in tribute to August Bier ${ }^{3}$ who first described the anesthesia produced as a direct diffusion of the anesthetic from the vessels to the adjacent tissues. Furthermore, with careful attention in details as not releasing the prematurely the tourniquet, and after release monitoring the patient during a little period, make this blockade one of the most reliable and effectives for the anesthesiologist.

The long action amino-amide local anesthetics such as bupivacaine and etidocaine have better margins of safety than the short acting drugs such as lidocaine and mepivacaine when appropriately injected, because they have a slower systemic absorption and are more potent when used in lower doses. Despite this margin of safety, bupivacaine used in IVRA can cause toxicity for cardiovascular system and $\mathrm{CNS}^{4}$, expressed by convulsions, decrease in the cardiac debit and the myocardium blood flow, ventricular fibrillation and arrhythmia with QRS waves larger when intravenous doses higher $\geq 75 \mathrm{mg}$ and $100 \mathrm{mg}$ to bupivacaine and levobupivacaine, respectively.

Recently, new formulations and concentrations of bupivacaine have transformed this local anesthetic is a good option for local anesthesia, especially for block on nerve trunks ${ }^{5,6}$. The hyperbaric local anesthetics increase the interstitial pressure and the power of diffusion in adjacent tissues because they have great density when compared with their pattern reference. The aim of this study was to evaluate the bupivacaine effects on IVRA and $\mathrm{BPB}$ on anesthesia, motor block and cardiovascular parameters in dogs.

\section{Methods}

This experiment was approved by the Ethic Commission of Animal Utilization (CEUA) from the Federal University of Mato Grosso do Sul, (UFMS), so that it agrees with the ethic principles of Brazilian College of Animal Experimentation. Fourteen adult dogs, from both sexes, averaging 10 kilograms $(\mathrm{kg})$ of body weight were provided from Control Center of Zoonoses from Campo Grande - MS Township. Before the initialization of the experiment, dogs were submitted to biochemical exams, haemogram and search of anterior diseases, with the purpose of evaluating its general health. Animals were kept in Faculty of Veterinary Medicine and Animal Science of Federal University of Mato Grosso do Sul state, during the whole experimental period.

Dogs were randomly allocated to two different groups with 7 animals each being BPB and IVRA using of $0.25 \%$ $(3.0 \mathrm{mg} / \mathrm{kg}$; mean dose $10 \mathrm{~mL})$ and $0.5 \%(0.5 \mathrm{mg} / \mathrm{kg}$; mean dose $4 \mathrm{~mL})$, respectively of bupivacaine plus glucose $(5 \mathrm{mg}+80 \mathrm{mg} / \mathrm{mL}$, respectively) without epinephrine. Food was withheld for $12 \mathrm{~h}$ and water for $4 \mathrm{~h}$ prior to procedures body weight was measured and annotated in protocols. As pre-anesthetic medication were used acepromazine, in dosage $0.1 \mathrm{mg} / \mathrm{kg}$ by intramuscular (IM) way in the posterior limb and the right cephalic vein was punctured, through a $20 \mathrm{SWG}$ catheter to provide $0.9 \%$ saline continuous and slowly. The doses of the both techniques for this study were performed in all animals in the left forelimb. The room temperature was kept constant at $24{ }^{\circ} \mathrm{C}$.

\section{Brachial plexus block}

For BPB group the was made the tricotomy and antisepsis using alcohol $70^{\circ} \mathrm{GL}$ and iodated alcohol $2 \%$ on the scapula-humeral articulation, following with an infiltrative local anesthesia with $2 \mathrm{~mL}$ of lidocaine $2 \%$. Sequentially after some minutes, was made a small incision on the skin immediately medial to scapula-humeral articulation and introduced an electrical nerve stimulation adjustable current settings: $0.5,1.0$ and $2.0 \mathrm{~mA}$, with current flow confirmation light, coupled in a $18 \mathrm{G}$ needle used as a guide for the probe tip of the nerve stimulator, below the scapula-humeral articulation and parallel to thoracic cavity in the sense of the costochondral junction. The nerve stimulator was initially used with $0.5 \mathrm{~mA}$ to ensure proximity to the nerve $(1 \mathrm{sec})$. After this, the nerve stimulator was withdrawal and a syringe containing the local anesthetic was then connected to the needle and if no blood is aspirated into the syringe the hyperbaric bupivacaine $(10 \mathrm{ml})$ was deposited close to the axillary artery and ventral branches of sixth, seventh, eighth cervical, and first thoracic spinal nerves. The main regions blocked were those responsible for the movement of the shoulder, elbow and carpus.

\section{Intravenous regional block}

In IVRA treatment, was injected acepromazine IM as cited above and shaved in the radio-cranial region. The limb was first desanguinated by wrapping it with an Esmarch bandage. A rubber tourniquet was placed around the limb proximal in the humerus above the humerus-radial articulation. Once the tourniquet was secured, the Esmarch was unwrapped, and $0.5 \mathrm{mg} / \mathrm{kg}$ of $0.5 \%$ hyperbaric bupivacaine was injected. The volume of hyperbaric bupivacaine was diluted with saline to a total volume of $4 \mathrm{~mL}$. IVRA solutions were administered slowly via the catheter over 1 min. Tourniquet pain was assessed by the presence of no pain or discomfort and worst pain and/or total discomfort. These evaluations were conducted by the same observer, just before and after of placing them. The main regions blocked are innervated by the radial, median, ulnar, musculo-cutaneous (cranial, medial and caudal) and axillary nerves. 


\section{Physiological measurements}

To understand the physiological reactions to the treatments, arterial pressure [systolic (SAP), diastolic (DAP), and mean (MAP)] was measured using a non-invasive device, with the cuff attached to the proximal third of the radius in order to measure the pressure in the brachial artery. The peripheral oxygen saturation $\left(\mathrm{SpO}_{2}\right)$ was measured through a sensor attached at the base of the ear. The heart rate (HR) was measured by electrocardiograph, and all these variables above were measured using a RX-300A cardiac monitor. Respiratory rate (RR) was measured by counting chest movements per minute.

To facilitate the data collection from sensitive block, the forelimb was divided in 5 regions being 1 - humerus-cranial; 2 - radio-tibia-cranial; 3- humerus-caudal; 4 - radio-tibia-caudal; 5 - metacarpus-phalanx. All parameters were evaluated at times 0 (baseline), 1 (after acepromazine) 5, 10, 15, 30 and every $60 \mathrm{~min}$ thereafter each treatment until the end of analgesia. All animals received a standard painful stimulus pricking the skin with a haemostatic forceps (superficial pain evaluation) and a 23-gauge needle inserted into the skin and the underlying tissues (deep muscle pricks) at the five different regions. The anesthetic effects were evaluated by the same person in both treatments. The following anesthetic scale was used: 1 - normal response to a painful stimulus; 2 - mild analgesia; 3 - moderate analgesia; 4 - analgesia; 5 - anesthesia, complete absence of response to a painful stimulus. Motor effects were evaluated observing the posture of the anesthetized member using the following scale: 1 - no motor block; 2 - mild incoordination of the member; 3 - Drag the dorsum of the foot on the floor when walking; 4 - Incoordination in the movement, but still supports the member slightly on the floor; 5 - Ptosis of the member not supporting the paw on the floor at the movement.

All data were analyzed using commercial statistical package. A randomized complete block design, in which time is a treatment and each animal is a block, was used for each drug. For the dependent variables HR, RR, SAP, DAP and MAP, an analysis of variance (ANOVA) was performed, and the pos-hoc Dunnett's test was applied when the treatment response differed from baseline (time 0). For anesthesia and motor-dependent variables, nonparametric statistic were used by applying Friedman's test, followed by multiple comparisons for ranked data by using Dunnett's test, with time 0 as a baseline. In each analysis, differences were considered significant if $P<0.05$.

\section{Results}

Both techniques studied produced anesthesia with variable duration; however BPB showed a superior duration as well as efficiency. The use of acepromazine allowed the animals stay calmer providing a good way to performance the proposed techniques. In the first week following the experiment was not related any sign of neurotoxicity in the animals caused by hyperbaric bupivacaine.

Four of the seven animals from IVRA, showed a painful reaction from the venous bupivacaine injection. In the BPB the technique used do not produced any painful reaction to the drug application, and the latency period was 15 minutes and the total duration was $456 \pm 94($ mean $\pm \mathrm{SD}$; Figure 1).

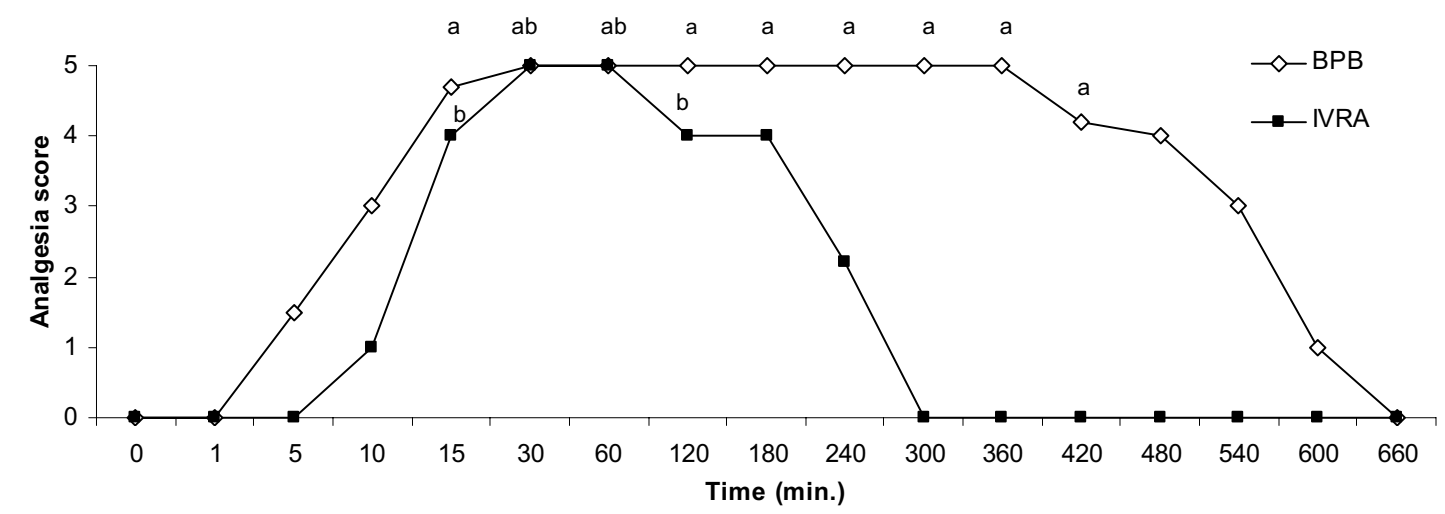

FIGURE 1 - Median scores of anesthesia for brachial plexus block (BPB; $\mathrm{n}=7$ ) and intravenous regional anesthesia (IVRA; $\mathrm{n}=7)$ in dogs using hyperbaric bupivacaine $0.25 \%(3.0 \mathrm{mg} / \mathrm{kg})$ e $0.5 \%(0.5 \mathrm{mg} / \mathrm{kg})$, respectively. The following scale was used: 1 - normal response to a painful stimulus; 2 - mild analgesia; 3 - moderate analgesia; 4 - analgesia; 5 - anesthesia, complete absence of response to a painful stimulus. Values for BPB ${ }^{(a)}$, IVRA $^{(\mathrm{b})}$ differed significantly $(P<0.05)$ from baseline (time 0$)$ values

On the other hand, the IVRA analgesia was displayed about 25-30 minutes after the drug, although two dogs began this period before. For this technique the analgesic period and the blocked regions were so much variables among the animals, being 30 minutes the shorter period (three animals) and 210 minutes the longer period (four animals), moreover no dogs showed complete block in all researched regions. In the same way, the motor block period was bigger in the BPB (30-420 minutes; when considered motor block score 5; Figure 2). 


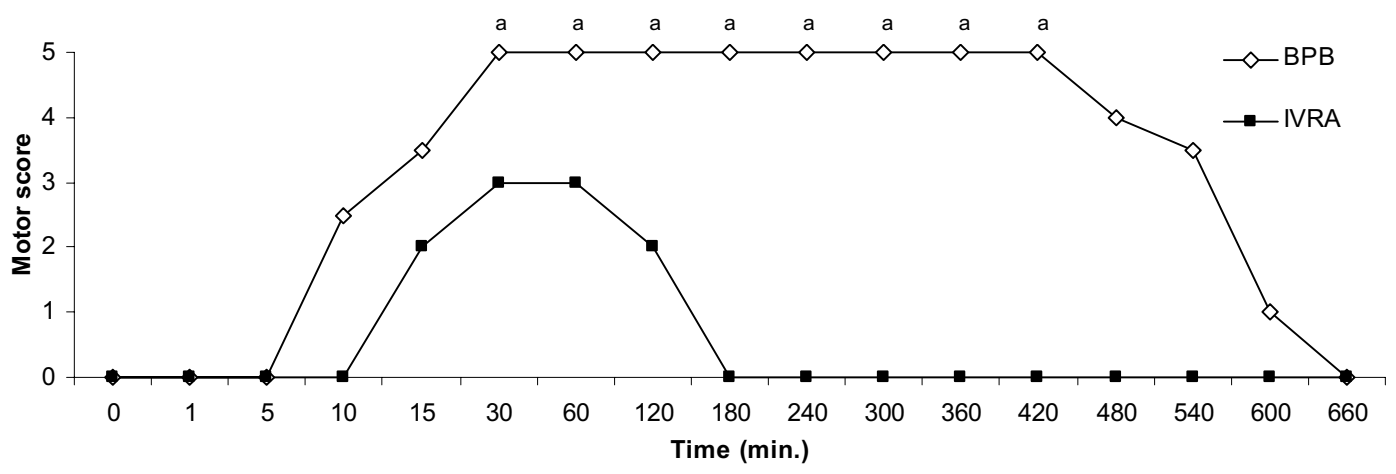

FIGURE 2 - Median scores of motor block for brachial plexus block (BPB; $\mathrm{n}=7$ ) and intravenous regional anesthesia (IVRA; $\mathrm{n}=7)$ in dogs using hyperbaric bupivacaine $0.25 \%(3.0 \mathrm{mg} / \mathrm{kg})$ e $0.5 \%(0.5 \mathrm{mg} / \mathrm{kg})$, respectively. Motor effects were evaluated observing the posture of the anesthetized member using the following scale: 1 - no ataxia; 2 - mild incoordination of the member; 3 - Drag the dorsum of the foot on the floor when walking; 4 - Incoordination in the movement, but still supports the member slightly on the floor; 5 - Ptosis of the member not supporting the paw on the floor at the movement. Values for BPB ${ }^{(a)}, \operatorname{IVRA}^{(b)}$ differed significantly $(P<0.05)$ from baseline (time 0$)$ values

IVRA only induced drag of dorsum of the foot on the floor when walking (score 3 ) for 30 to $60 \mathrm{~min}$. Five from seven animals in the BPB group showed ptosis (Figure 3) in the blocked member, with lower duration than the analgesic period.
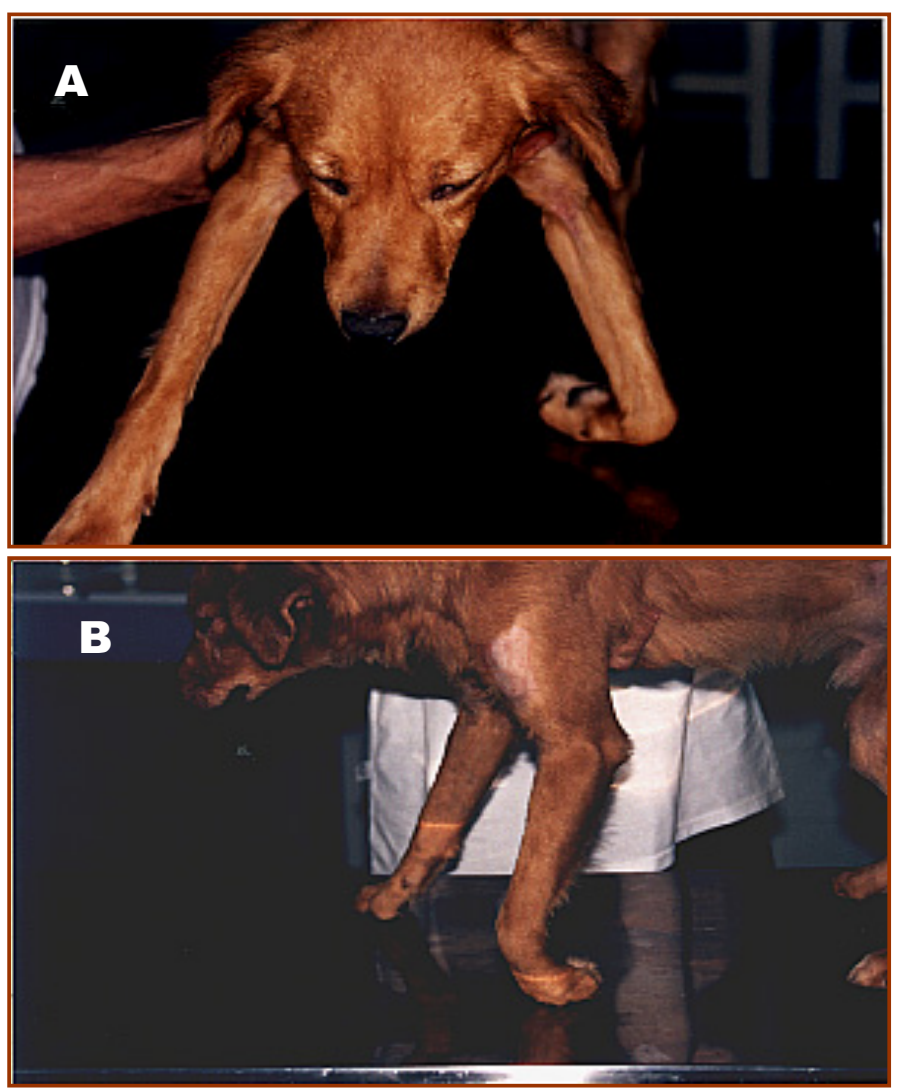

FIGURE 3 - Front (A) and lateral (B) views of a ptosis of the left limb produced by a brachial plexus block using hyperbaric bupivacaine $0.25 \%(3.0 \mathrm{mg} / \mathrm{kg}$; mean volume $10 \mathrm{ml})$ in an adult dog
There was no difference $(P>0.05)$ in HR for both groups, however all dogs showed arrhythmia during the anesthetic period. In the same way, for the IVRA group was not found significant difference $(P>0.05)$ for the cardiovascular aspects (SAP, DAP and MAP), as well as for DAP and MAP from BPB, although the SAP from 30 to 360 minutes was decreased $(P<0.05)$. For both treatments the RR was decreased, showing a bigger period to $\mathrm{BPB}$ where the depression began from $5 \mathrm{~min}$ to $660 \mathrm{~min}$ and in IVRA it began at 30 min going low until $300 \mathrm{~min}$.

\section{Discussion}

Hyperbaric bupivacaine at $0.5 \%$ and $0.25 \%$ was efficient for both brachial plexus block and intravenous regional anesthesia, respectively in dog's front limb. Hyperbaric local anesthetics have been used for many years due to their short duration of action and the safety of the procedure ${ }^{7}$. Compared to plain solutions, hyperbaric solutions might provide a more predictable block with fewer side effects, such as high block, hypotension, nausea, vomiting, and pruritus ${ }^{8}$. As hyperbaric solutions have higher density when compared with a reference standard, they develop enough interstitial pressure to cause diffusion of injected material in the dependent regions. The blocked regions were innervated by the radial, median, ulnar, musculo-cutaneous and axillary nerves, and in every region of the limb the BPB blocked more effectively. In the IVRA, most part of the regions was not totally blocked, maybe because the drug has not diffused efficiently to the adjacent tissue. Although there are controversies about the place of putting the tourniquet, if the limb (distal to the carpus) or forelimb (above the humerus-radial articulation) because of the theoretical risk of local anesthetic leakage through the interosseous vessels. One study in humans demonstrated that forearm IVRA results in tourniquet leakage comparable to conventional IVRA and is potentially safer because the required dose of local anesthetic is smaller ${ }^{10}$. Moreover, the use of the tourniquet showed to be painful, what can be avoided using 
lidocaine local infiltration previously in the place where the tourniquet will be fixed ${ }^{11}$. To facilitate the technique in BPB, was utilized an electrical nerve stimulation to localize the nerves which compose the brachial plexus ${ }^{2,3}$, however we can find other technique used for this aim, for instance the multiple injections and the use of an electrical nerve stimulation in $\operatorname{dogs}^{12,13}$, catheter with a tube in $\operatorname{dogs}^{14}$ and the utilization of an inserted cannula $\left(30^{\circ}\right.$ in relation to the skin) in the axillary region direction was used in children ${ }^{15}$. By the way, in plexus brachial block in the most part of these researches is used the localization of the axillary artery ${ }^{2,12,15}$.

Was found a variation in the anesthesia period between both techniques. The BPB anesthetize the blocked member for a long time about $8.3 \mathrm{~h}$ similar to another study which used multiple injections in dogs with $0.375 \%$ bupivacaine with vasoconstrictor $(4 \mathrm{mg} / \mathrm{kg})$ got an $11 \mathrm{~h}$ analgesic period ${ }^{12}$. In this sense, a study aiming a long duration anesthesia comparing $0.5 \%$ ropivacaine and $0.5 \%$ bupivacaine in plexus brachial block in humans do not found significant difference in relation the beginning and duration of the anesthesia between the two treatments $(7.1$ and $11.5 \mathrm{~h}$, respectively $)^{16}$. Probably, the period of analgesia of this experiment was lower due to the low concentration $(0.25 \%)$ and the solution used was without vasoconstrictor.

On the other hand the IVRA using $0.5 \%$ hyperbaric bupivacaine showed just 30-60 min of anesthesia, moreover in this treatment was found a high variation among the animals, starting from 30 to 210 min of block. This variation on the analgesic period was showed in a study with humans with $27.5 \mathrm{~min}(5-40 \mathrm{~min})$ using levobupivacaine $(0,125 \%)^{17}$. The total analgesic period from our experiment was superior, maybe due the specie, formulation and concentration. Complications of the IVRA resulting from blood-flow deprivation to the limb or from the dose of anesthetic used do not occur if the procedure is limited to $90 \mathrm{~min}$.

The local anesthetics through the subarachnoid space produce a sympathetic block that result in peripheral vasodilatation. The arterial pressure usually is not changed significantly for this block in normovolemic animals. Cardiac alterations are observed just when there is a huge plasmatic concentration of the local drug or through an accidental intravascular injection. The bupivacaine in plasmatic levels of 3 to $4 \mu \mathrm{g} / \mathrm{ml}$ can have adverse effects in intraventricular conduction and on the cardiac contraction for suppression of the baroreceptors sensibility ${ }^{18}$, which could trigger a ventricular fibrillation ${ }^{19}$. The IVRA group do not show vascular alterations in the dosage studied, in agreement with other study ${ }^{17}$. On the other hand was seen a significant depression on the systolic pressure in the BPB. Furthermore, this effect can occur for the capacity of the bupivacaine to block quickly the sodium channels during the systole, dissociating more slowly in the diastole ${ }^{20}$.

All the animals of both groups showed arrhythmia after the injection of bupivacaine, and it is because this local anesthetic depresses the neural conduction which promote an wave QRS enlargement causing ventricular arrhythmia frequently fatal ${ }^{4,19}$. By the way the accidental intravenous injection of bupivacaine is fatal and the patients do not respond to resuscitation ${ }^{21,22}$, although the news formulations of bupivacaine have less toxicity. For example, in a study where $1 \mathrm{mg} / \mathrm{kg}+0.4 \mathrm{mg} / \mathrm{kg} / \mathrm{min}$ of bupivacaine infusion in dogs and pigs, to get levels of 0.4 to $1.2 \mu \mathrm{g} / \mathrm{ml}$, induced cardiac arrhythmia with block atrioventricular of 1 e $2^{\circ}$ degree $^{19}$. In this way, healthy patients who received intravenous infusion of racemic bupivacaine or levobupivacaine had less effect on the cardiac contractibility ${ }^{23}$. Nowadays, bupivacaine is the local anesthetic with the lower degree of motor block and less neurotoxicity ${ }^{24}$, being most used to epidural and subarachnoid blocks in humans ${ }^{5}$ and equines ${ }^{6}$. In this study was found a depression in respiratory rate in both groups during the anesthetic period, which may be related with the tranquilization of the animals with acepromazine.

By the way, no animals for both groups do not showed any effects in CNS after receive the hyperbaric bupivacaine, although local anesthetics as lidocaine, ropivacaine and bupivacaine in clinic doses may show effects of CNS intoxication for instance tinnitus, lightheadedness, blurred vision, seizures, metallic taste, dry mouth, numbness of the tongue and lips and incoordination ${ }^{1,25}$.

\section{Conclusion}

The utilization of hyperbaric bupivacaine $0.25 \%$ in BPB produces three times more anesthesia of front limb than the same solution in $0.5 \%$ in IVRA in dogs, with ptosis of the blocked member and little interference in the cardiovascular system, but with decrease in respiratory rate.

\section{References}

1. Joubert KE. Electrical nerve stimulation as an aid to the placement of a brachial plexus. J South Afr Vet Assoc. 2002;73:216-8.

2. Wenger S. Brachial plexus block using electrolocation for pancarpal arthrodesis in a dog. Vet Anesth Analg. 2004;31:272-5.

3. Bier A. Uber einen neuen Weg Lokälanästhesie na den Gliedmassen zu erzengen. Arch Klin Chir. 1908;86:1007-16.

4. Huang YF, Pryor ME, Mather LE, Veering BT. Cardiovascular and central nervous system effects of intravenous levobupivacaine and bupivacaine in sheep. Anesth Analg. 1998;86:797-804.

5. Gazzotti F, Bertellini E, Tassi A. Best indications for local anaesthetics: bupivacaine. Minerva Anesthesiol. 2001;67:9-14.

6. DeRossi R, Sampaio BFB, Varela JV, Junqueira AL. Perineal analgesia and hemodynamic effects of the epidural administration of meperidine or hyperbaric bupivacaine in conscious horses. Can Vet J. 2004;45:42-7.

7. Keld DB, Hein L, Dalgaard M, Krogh L, Rodt SA. The incidence of transient neurologic symptoms (TNS) after spinal anaesthesia in patients undergoing surgery in the supine position. Hyperbaric lidocaine 5\% versus hyperbaric bupivacaine $0.5 \%$. Acta Anaesthesiol Scand. 2000;44:285-90. 8. Hocking G, Wildsmith JA. Intrathecal drug spread. Br J Anaesth. 2004;93:568-78.

9. DeRossi R, Frazílio FO, Miguel GLS, Kassab TA. Comparison of 2\% lidocaine and hyperbaric 5\% lidocaine for caudal epidural analgesia in horses. J Equine Vet Sci. 2005;25:198-205.

10.Coleman MM, Peng PW, Regan JM, Chan VWS, Hendler AL. Quantitative comparison of leakage under the tourniquet in forearm versus conventional intravenous regional anesthesia. Anesth Analg. 1999;89:1482-6.

11. Estebe JP, Gentili ME, Langlois, G, Mouilleron P, Bernard F, Ecoffey C. Lidocaine priming reduces tourniquet pain during intravenous regional anesthesia: A preliminary study. Reg Anesth Pain Med. 2003;28:120-3.

12. Futema F, Fantoni DT, Auler Jr JOC, Cortopassi SRG, Acaui A, Stopiglia AJ. A new brachial plexus block technique in dogs. Vet Anesth Analg. 2002;29:133-9.

13. Sia S, Lepri A, Campolo MC, Fiaschi R. Four-injection brachial plexus block using peripheral nerve stimulator: a comparison between axillary and humeral approaches. Anesth Analg. 2002;95:1075-9. 
14. Moens NM, Caulkett NA. The use of a catheter to provide brachial plexus block in dogs. Can Vet J. 2000;41:685-9.

15. Thornton KL, Sacks MD, Hall R, Bingham R. Comparison of $0.2 \%$ ropivacaine and $0.25 \%$ bupivacaine for axillary brachial plexus blocks in paediatric hand surgery. Paed Anesth. 2003;13:405-9.

16. Vainionpaa VA, Haavisto ET, Huha TM. A clinical and pharmacokinetic comparison of ropivacaine and bupivacaine in axillary plesys block. Anesth Analg. 1995;81:534-8.

17. Atanassoff PG, Aouad R, Hartmannsgruber MWB, Halaszynski T. Levobupivacaine $0.125 \%$ and lidocaine $0.5 \%$ for intravenous regional anesthesia in volunteers. Anesthesiology. 2002;97:325-8.

18. Watanabe Y, Dohi S, Iida H, Ishiyama T, Tashiro T, Shimonaka H. The effects of systemic bupivacaine on baroreflex sensitivity in dogs. J Anesthesiol. 1995;44:1097-101.

19. Timour Q, Gaillard P, Bui-Xuan B, Vial T, Evreux J, Freyrz M. Cardiac accidents of locoregional anaesthesia: experimental study of risk factors with bupivacaine. Bull Acad Natle Med. 1998:182:217-32.
20. Clarkson CW, Hondeghem LM. Mechanism for bupivacaine depression of cardiac conduction: fast block of sodium channels during the action potential with slow recovery from block during diastole. Anesthesiology. 1985;62:396-405.

21. Ware RJ. Intravenous regional analgesia using bupivacaine: a double blind comparison with lignocaine. Anaesthesia. 1979;51:285-7.

22. Heath ML. Deaths after intravenous regional anaesthesia. Br Med J. 1982;285:913-4.

23. Bardsley H, Gristwood R, Baker H, Watson N, Nimmo WA. A comparison of the cardiovascular effects of levobupivacaine and rac-bupivacaine following intravenous administration to healthy volunteers. Br J Clin Pharmacol. 1998;46:245-9.

24. Hodgson PS, Neal JM, Pollock JE, Liu SS. The neurotoxicity of drugs given intrathecally (Spinal). Anesth Analg. 1999;88:797-809.

25. Brown DL, Ransom DM, Hall JA, Leicht CH, Schroeder DR. Regional anesthesia and local anesthetic-induced systemic toxicity seizure frequency and accompanying cardiovascular changes. Anesth Analg. 1995;81:321-8.

Conflict of interest: none

Financial source: none

\section{Correspondence:}

Dr. Rafael DeRossi

Faculdade de Medicina Veterinária

Universidade Federal do Mato Grosso do Sul

Caixa Postal 549

79070-900 Campo Grande - MS Brazil

derossi@nin.ufms.br

Received: December 14, 2009

Review: February 12, 2010

Accepted: March 18, 2010

\section{How to cite this article}

Macedo GG, DeRossi R, Frazílio FO. Evaluation of two regional anesthetic methods on the front limb of dogs using hyperbaric bupivacaine. Acta Cir Bras. [serial on the Internet] 2010 May-June;25(3). Available from URL: http://www.scielo.br/acb 